\title{
Bridging the Learning Gap: Cross-Cultural Learning and Teaching through Distance
}

\author{
Delores V. Mullings ${ }^{1, *}$ \\ ${ }^{1}$ School of Social Work, Memorial University of Newfoundland and Labrador, St. John's, Canada \\ *Correspondence: School of Social Work, Memorial University of Newfoundland and Labrador, St. John's College, St. \\ John's, NL., A1C 5S7, Canada. Tel: 1-709-864-3419. E-mail: dmullings@mun.ca
}

Received: August 8, 2014

Accepted: February 10, $2015 \quad$ Online Published: March 12, 2015

doi:10.5430/wje.v5n2p1

URL: http://dx.doi.org/10.5430/wje.v5n2p1

\begin{abstract}
This project engaged students, practitioners, and educators from University of Labor and Social Affairs, Cau Giay District, Hanoi and Newfoundland and Labrador, Canada, in a cross-cultural distance learning and teaching collaboration. Two groups met simultaneously through Skype videoconferencing to discuss and learn about field supervision and about social policy that supports women who experience family violence. This collaboration strongly demonstrates the usefulness of technology in bridging the learning divide and achieving meaningful cross-cultural educational exchanges from a distance.
\end{abstract}

Keywords: cross-cultural education; videoconferencing; field education; cross-cultural learning and teaching; education collaboration

\section{Introduction}

Institutions of higher learning and teaching have adjusted to the changing social environment in order to meet the unique needs of their learning populations. Technology is used as a means to provide accessible education to students from a distance. In addition, we live in an increasingly global world and we are expected to know, understand, and be sensitive to the needs of people from different cultures. Western academic institutions, including Memorial University (MUN), have embraced the internationalization of education and continue to implement strategies to attract and retain new immigrants. Memorial being the only university in the province of Newfoundland and Labrador (NL), needs to develop cross-cultural collaborative relationships in this global context in order to become leaders in providing accessible, innovative, and learner-centered educational opportunities. Within this context, MUN School of Social Work and the School of Nursing assisted with the development and implementation of a five year poverty reduction strategy with social workers at University of Labor and Social Affairs, Cau Giay District, Hanoi, Vietnam (ULSA). The project "used a community capacity-building approach in partnership with ULSA to develop and sustain an education program including training the trainers and facilitating community outreach" (Gein, Taylor, Barter, Nguyen, Bui, \& Nguyen, 2007 p. 305). Given the history of collaborative work between the two universities, this author received funding to embark on an experiential learning project for groups of students at MUN School of Social Work and ULSA School of Social Work to interact with each other through the use of distance technology. This paper reports the learning outcomes of the project.

\section{Review of Related Literature}

The world of teaching and learning has changed significantly with advancements in communications technology. Institutions of higher learning are equipped with wireless internet, which allows student access to the World Wide Web using their computers or hand-held devices such as telephones, tablets, and ipods. Students click and tap away to connect with the highway of knowledge, accessing information within minutes of its occurrence. Institutions of higher learning are now capitalizing on students' technological savvy by using videoconferencing as a means of transforming the standard classroom into innovative learning and teaching centers. Consequently, a bourgeoning literature exists in which educators share their experiences of learning and teaching collaboration with others from 
across the globe. Anucha (2008 section The Process of Building Equitable Collaborations, para. 6) discussed reciprocity as a key principle underlying the collaboration between University of Benin and three Canadian universities and further argued that participants emphasized the need for relationships based on reciprocity and methods that did not reproduce the "exploitative practices of colonialism". Brydon et. al (2012) highlighted the core concept that learning flows between partners in their work with the University of Papua New Guinea and Monash University, Australia. Dean (2013) detailed teaching experiences among women social work instructors from both the Global South and North. Kreitzer and Wilson (2010) explored the creation of relationships rooted in solidarity as opposed to partnership. In discussion about social work partnerships between institutions in the United States, India and Bangladesh, Mukherjee (2011) noted the importance of "comparative policy analysis that broadens the participants' horizons and renders them with new perspectives about domestic practice" (section Social Exchange and Partnership Learning, para. 19). Vincent (2010) wrote about the importance of the "collective ownership of goals" (as cited in Bronstein 2003, section Bronstein's Model for Interdisciplinary Collaboration, para. 7) as demonstrated in a Kenyan - United States collaboration. Discussion with regard to the use of video conferencing has also become prominent. For instance, Fry and Hin (2006), Hrastinski (2006), and Meyer (2004) have demonstrated in their studies how to use videoconferencing and class discussions as andragogical and instructive tools in higher learning. Similarly, Gregersen and Youdina (2008) have shared their experiences of cross-cultural learning in the research they did with students from Russia and the United States, and Harkins and Nobes (2008) have examined educational collaboration between a Canadian university and several universities in Bermuda and the Caribbean. Many others are involved with innovative learning and teaching in the classroom. Highlighting teaching innovation that can occur in classrooms through online teaching and learning, Durant, Mann, Rose and Stix (2007) described a graduate seminar that involved nine universities, 78 students and 14 guest speakers. Kan's (2011) detailed description of cultural exchanges between Chinese and U.S. college students in a visual arts class provided a glimpse into how online teaching and learning can shape cultural perception of people. In their research Bohemia and Ghassan (2012) also demonstrated lessons that can be drawn from online teaching and learning in an industrial design project that involved 240 students and 18 academic staff from universities in Japan, Australia, Korea, China, Taiwan, England, and Canada. Scott, Castañeda, Quick, and Linney (2009) reported benefits that accrued from a six-month, peer-support learning community organized and managed by students. The program was facilitated through videoconferencing. These are but a few examples of how teaching innovation is being introduced and managed for cross-cultural learning and teaching benefits.

According to Gregersen and Youdina (2008) "because of advancements in transportation and information systems technology, intercultural contact has accelerated, compelling the educational system to address the surging need for more effective intercultural communication" (p. 1). While these studies speak about the strengths and benefits that can accrue from online teaching and learning, Gouthro (2004) discussed power relations with respect to gender inequity; and later Pelech and Macpherson (2009)_questioned and warned about the potential threats of using technology in the global classroom, especially if adequate measures are not taken to address questions of exploitation and disempowerment of learners from the Global South, who are already vulnerable to asymmetrical power relations between them and those in the Global North. The researcher remained cognizant of the warnings that Pelech and Macpherson (2009) alluded to in respect to the potentially exploitative nature of cross-cultural collaboration between those in the Global South and Global North. It seems that post-secondary institutions are clamoring to attract students from the South, but studies show that the students are not interacting together (Arkoudis et al., 2013), and often the overwhelming beneficiaries of those partnerships are realized in the North. Many universities seem to believe that projecting pictures of beaming Brown and Black faces is sufficient to indicate their commitment to their partners in the South.

This research complements that of Kan (2011) and Harkins and Nobes (2008), for example, in the realization of challenges inherent in organizing educational activities when the time zones and cultures are significantly different. However, this work departs from the usual cross-cultural educational experience using videoconferencing. Specifically, the learners and the educators were jointly involved in the construction of the learning material, and the group in Hanoi determined what was best for their learning. They determined how they wanted to participate in the experiential learning, and this provided space for the inclusion of social workers-who offered their perspectives as community practitioners - alongside learners in the educational exchange. These characteristics of our project are further explored later in the paper.

\section{Distance Education at Memorial University - Background}

The province of Newfoundland and Labrador is the most eastern part of North America and is affectionately called 
"The Edge" by the province's Ministry of Tourism. Practically surrounded by the North Atlantic Ocean and straddling two time zones, the land mass is enormous, almost as large as California, but much of the province's land mass lies in rural and remote areas, with the major urban center being St. John's (Government of Newfoundland and Labrador, n.d.). The population is just over 500000 with a rapidly growing aging cohort of which almost $15.2 \%$ are older than 65 years (Statistics Canada, 2010). The sparseness of the population and communities located along costal areas makes it difficult for many people to access resources and services. Out-migration from smaller communities has created barriers for older people living alone. Aboriginal peoples have historically inhabited the land; however, the NL population is a majority White settler society. Recently, an increasing number of racialized people and immigrants have entered the province, but a lack of infrastructure has motivated many to leave within a short period. The province has also experienced economic success with the production of oil and gas. This success has opened the skilled labour market, in which people outside the province fill many of these new positions (Government of Newfoundland and Labrador, 2007). Access to education is even more important so that Newfoundlanders can assume some of these increasingly technical and highly skilled jobs.

Memorial has satellite campuses in several locations throughout the province. However, accessing a university education in the province is challenging for students, many of whom must leave home to enroll in the programs of their choice. While MUN's tuition is one of the lowest in the country, housing and the cost of living are extremely high, in contrast to very low student income and high poverty rates. Therefore, the MUN-based Distance Education, Learning and Teaching Support (DELTS) is a significant resource for the province in facilitating access to a university education. Through online technology, DELTS offers accredited degrees from MUN to students across the province. This program provides an opportunity to many students who otherwise could not attend university in the province. DELTS also encourages innovative learning and teaching through various means including a grants program. The author submitted a proposal and received funding that provided the opportunity to engage in experiential learning and teaching activities.

\section{Methodology}

This paper, reports on a qualitative study of four groups of students and practitioners, two in ULSA School of Social Work Cau Giay District, Hanoi, Vietnam and two in St John's Newfoundland, participated in videoconferencing group discussions about social work practice and supervision. The goal of the study was to: a) explore and critically examine how experiential learning can improve students' learning experience, b) foster cross-cultural distance teaching development and c) develop an appreciation for racial and cultural differences in social work education and supervision. The group discussions occurred within a two week period; however, the preparation for the discussions occurred over the 12 weeks during the winter semester between January and April 2012. The data in this paper originate from planning meetings and include electronic sources such as electronic mail, summaries of Skype conversations, and written notes that were taken during and after meetings and videoconferencing sessions. This experiential learning and teaching was a collaboration between MUN School of Social work and ULSA Schools of Social Work, each with two group of students. Similar to Harkins and Nobes (2008), Professor Huong and this researcher arranged the learning activities by negotiating and effectively creating an inclusive teaching environment that valued the contributions of both groups of students and practitioners. Meetings were scheduled through Skype and other communication was done through electronic mail as needed. Possible subject areas about what to include in the class exchange were discussed in addition to information about various possible participants, and on the logistics of conducting the class (length of each discussion, approach and possible material for each session, class format, number of groups, number of participants per group, and their physical locations). The University of Vietnam does not have videoconferencing facilities, so it was decided that using Skype videoconferencing would be an easy alternative to encourage and motivate participation. Rather than having formal lectures as originally proposed, an open-format dialogue focused on two areas was engaged. In consultation with faculty, students decided the topic areas and co-created guided questions to encourage a more effective learning exchange and to promote cross-cultural understanding. The areas of focus were: a) an area of concern to professional practice (social work supervision) and b) current events highlighted in local and national media coverage (family violence). The questions were as follows:

Questions from MUN School of Social Work (Leadership and Social Justice Sections 81 and 82):

- Please comment on how field supervision works in your agencies: Do you have regular supervision? When does this occur? What are the roles of the supervisee and the supervisor? Do you consider how supervision (or lack of it) may impact how you work with people who use your services? 
- Are there tensions with field supervision in both large and smaller work environments? If so, what are some of those tensions, how are they addressed, and by whom?

- What kind of support do workers receive in attending to job-related stress? If any of these supports are through policy (e.g., sick benefits under an employment policy), please share what they are and how they are implemented.

Questions from ULSA students and practitioners:

- Please share general information about domestic violence in your country: a) situation, b) number, c) causes.

- What are the practice models and policies for victims of domestic violence, and the strengths and weaknesses of these?

- What effective programs and services for do you have for victims of domestic violence?

- How do you raise awareness for the community in combating and dealing with issues of domestic violence?

- What cultural differences exist (between North America and Asia) in helping victims of domestic violence?

- What strategies do you use to ensure that people (doctors, community leaders, neighbours, etc.) do compulsory reporting in cases of domestic violence?

- How do you measure and identify legitimate claims of domestic violence case?

All questions were distributed to both groups of students prior to the class discussion. Once the topics were decided, literature was provided for each group of students to review prior to attending the class. Students self-selected the area and time of day they wanted to participate in the discussion.

\subsection{Learning and Teaching Process}

The collaborative class discussions occurred in two separate sessions accounting for four groups of students - two in St. John's, NL, and two in Hanoi, Vietnam. Initially there were a total of 12 students from MUN and 17 from ULSA. However, time zone constraints and illnesses affected the number of individuals who eventually participated. Participants from Vietnam included undergraduate and graduate students and experienced field practitioners. Some practitioners had many years of experience, and students ranged from second year undergraduate to final semester graduates. All students from MUN were from Social Justice and Social Work Leadership (two sections of a Master of Social Work distance course) and all had at least three years of direct practice experience. The group discussions occurred through Skype videoconferencing. Two faculty members from ULSA participated each one facilitated a discussion group. The faculty member from MUN facilitated both groups in NL. Each topic area was registered as a chat group on Skype: Faculty members were registered in both groups, while students and practitioners were registered only in the group in which they agreed to participate. All MUN participants were signed in to their respective group 60 minutes prior to the actual discussion. During this time technical difficulties were identified and resolved. When everyone was signed into their respective Skype chat group, as agreed, the discussion was initiated with welcome and introductions, intent of the discussions, and then the first question was read. The questions were asked until the discussion ended naturally or internet disruptions occurred. The session was facilitated so that each group got an opportunity to contribute to the discussion. The class format was discussion- oriented and informal.

\subsection{Bridging the Learning and Teaching Gap}

We bridged the learning gaps among students, practitioners, and faculty by creating groups of individuals who otherwise would never have the opportunity to learn and teach together. The MUN students lived in various provinces across Canada and only communicated within the infrastructure of DELTS through the Desire to Learn (D2L) technological environment as registered students in the social work program. This group of students communicated with each other several times per week within their scheduled courses. The practitioners and students in Hanoi would not likely meet in a classroom setting to learn together. Some of the students in Hanoi do not have internet access at home and would not be able to participate in the activities; the local context dictated how individuals could be engaged (Rye \& Støkken, 2012). Under normal circumstances, two professors on two different continents would not share a classroom as we did during these learning activities. We bridged the learning gap through the use of technology to bring all the students and practitioners together to share ideas cross-culturally in real time. Professors helped to guide the learning by sharing knowledge and experience and therefore offered effective facilitation (Law \& Nguyen-Ngoc, 
2009). Each professor influenced the learning of all students simultaneously, and the students and practitioners contributed to each other's learning and understanding of cross-cultural issues discussed. The students and practitioners learned from each other about their respective cultural traditions in dealing with specific social issues.

\section{Limitations}

The research is limited in a number of ways and therefore, caution must be used when reviewing and interpreting the information. The data collection is limited by the method and small sample population that were involved in the group discussion as well as the different mixture of participants' experiences. For example, group participants ranged undergraduate (various levels) to seasoned practitioners in Hanoi while all the participants from MUN were students but were also practitioners. The group discussion experience was limited by the lack of technological resources that are accessible to institutions of higher learning in the Global South (Gouthro, 2004; Perraton, 2000; Rumble, 2001) and the difference in time zones. The 12-hour time zone difference created limitations for some participants and was a significant barrier to their participation. The uncertainty of internet connectivity, given the need to rely on Skype as our means of communication proved extremely challenging with repeated disconnection and subsequent failure to reconnect to communicate with each other. In addition, the author's reflection and conclusion is subjective in that they interject the perspective of the author which is not based on scientific data; therefore, major conclusion cannot be drawn from the information presented. This area of learning and teaching collaboration is potentially useful for cross-cultural education; therefore, further investigation needs to include a scientific methodology with clear research questions, method of data collection and analysis. The next section discusses some of the learning outcomes in the project.

\section{Outcome}

Group 1 occurred on Tuesday, March 27, 2012, at 9:30 pm (NL time) and Group 2 on Wednesday, March 28, 2012, at 9:00 am (NL time). Group 1 discussed social worker stress and Group 2 discussed violence against women. Group 1 consisted of eight participants from ULSA - four students, three practitioners, and one faculty member. A misunderstanding with the agreed times precipitated a 60-minute delay in beginning the first class discussion. Consequently, this affected the length of time some participants were able to participate. Five participants began the discussion from MUN-four students and one faculty member. Similar to problems Reed and Woodruff (1995) discussed, Group 1 experienced significant technical difficulties with internet connectivity. The lines were frequently interrupted, and in some cases voice distortions were experience and that meant MUN's participants were unable to clearly hear participants from ULSA. The discussion ended prematurely after 50 minutes, when the groups were unable to reestablish connectivity. Group 2 consisted of five participants from ULSA - four undergraduate students and one faculty member-while MUN's participants were three students and one faculty member. The discussion began as planned, continued without technical difficulties, and concluded after 77 minutes. Participants from ULSA met on the university campus in one classroom. All participants from MUN used their individual computers at their places of work.

\subsection{Cross-cultural Learning and Understanding - Family Violence}

Through discussion and informal feedback, each group of participants shared their individual learning based on their participation in the discussion. Similar to Sandmann, Reischmann, and Kim, (2007), the groups used the discussion forum to transcend the barriers of time, geographic location, and culture. Through verbal exchange, MUN students learned that Vietnam has few social policies to support women and children who experience family violence, and in fact community support is almost non-existent. Professionals in Hanoi are not mandated to report child abuse or provide any level of support to families. Family violence is still considered a private affair; therefore, allied health professionals have different and individual approaches to helping families who experience violence. Further, we learned that police officers are more likely to scold male perpetrators and admonish them for having poor attitude towards their families and then request a change in their behavior. The MUN students voiced surprise at the lack of policy in Vietnam as if forgetting that our policies and laws, while seemingly sophisticated in theory, are often ineffective. The students from ULSA learned that Canada has many social policies and practices to deal with family violence. They were surprised that Canada has mandatory charging for abusers and that women can also be arrested and charged for defending themselves if male perpetrators have alleged that they physically harmed them. The group from ULSA identified the contradictions in Canadian policy aimed at protecting victims of family violence, especially in light of frequent assaults and murders. The MUN students were unable to articulate a clear rationale why male 
partners had the opportunity to murder estranged partners even with laws such as peace bonds. The group from ULSA concluded that in spite Canada's policies, laws, and programs to protect women who experience family violence, many still suffered similar fates as those in Vietnam, a country with no policy to protect victims. Did the inclusion of seasoned practitioners and graduate students helped to move the analysis to a more sophisticated level?

\subsection{Cross-cultural Learning and Understanding - Social Work Supervision}

Similar experiences were identified in the discussion around worker stress and supervision. This discussion had similar issues for both groups: They identified a lack of support and, specifically, a lack of consistent supervision. Practitioners in ULSA noted that they are struggling to be seen as legitimate professionals. This lack has caused some barriers to their receiving professional support. The ULSA students noted that the social work program at ULSA is not accredited; therefore, individuals who graduate from the school are not qualified to provide social work supervision. However, some community and government agencies are using professionals from Australia to address their supervision needs. The students in Canada at MUN identified that many of their immediate supervisors were equally unqualified to offer effective supervision to field workers, and many do not have regular supervision regardless of their place of work. However, given that schools of social work in Canada are accredited, social work field supervisors are sometimes post-graduate level (Master of Social Work) with many years of experience. Both groups, however, were clear that they often do not receive adequate field supervision. They concluded that in spite of Canada's experience with social work programs and accreditation standards, Canadian field workers are equally disadvantaged by lack of supervision support as compared with those practicing in Vietnam.

\section{Reflections}

Some researchers (Altbach, 2002; Feast \& Bretag, 2005) suggest that international education ought to be designed according to Western curricula. Although this was a short educational exchange, it was important to disregard notions of Western superiority and not focus on MUN's needs only. The activity was designed to achieve cross-cultural learning and teaching collaboration through distance. Many universities in the Global South, the area of interest, do not have videoconferencing capabilities (Perraton, 2000; Rumble, 2001); therefore, Skype technology, which is more accessible, was used. This researcher assumed that the learning and teaching would occur with a North American-style uniformity involving only students; however, individuals from ULSA identified different learning needs, which included community practitioners and students in various levels of their education. The particulars were adjusted to the needs of the group in Hanoi, which enabled a richer discussion and created sensitivity to a beginning understanding of how educational needs can be different depending on the cultural group. More importantly, the questions generated significant discussion from a cross-cultural perspective. Each group gained much understanding about violence against women and the institutional and informal community policies available to deal with family violence from a different cultural perspective. The learning and teaching exchange exposed MUN's students to people in a culture that is entirely different from their own both as Canadians and as Newfoundlanders. This experience provided an encounter that acted as a bridge, helping students and practitioners in both countries to begin to understand their colleagues in Vietnam and Canada from their unique cultural perspectives; and it provided innovative program delivery. What are some questions that must be asked in spite the apparent success of the encounter between the groups?

Some of the MUN students used professional jargon - could this have been a potential barrier to the Hanoi individuals' ability to understand parts of the context of the discussion? In addition, was the Canadian and NL diction and enunciation difficult for the ULSA groups to understand at times? Similarly, did the MUN students encounter a language barrier when they consistently ask the Hanoi participants to repeat what they had said? These are important questions given that participants on both sides frequently requested that information be repeated even when internet connectivity was clear. Was this the case of technology not being neutral as Bohemia and Ghassen (2012) have reminded us that "it is vital to recognize that technology is not culturally neutral, especially in international educational collaborative projects" (p. 15). Other questions need to be asked: how can this type of exchange help to prepare both groups of social workers to work cross-culturally with different groups of immigrants who are service recipients in their respective countries? Did the project improve the overall learning experience for four groups of participants at various levels in their education and practice? Should the number of times the groups meet be increased? Do the participants need to be separated by levels of education (e.g. undergraduates) and practitioners? What aspects of the project could be evaluated to ensure an enhanced educational experience? This project is only a beginning to the vase cross-cultural learning and teaching opportunities and adjustments can be made to improve the quality of learning experience. 


\subsection{Other Considerations}

Memorial, through DELTS, agreed with the proposal to provide social work-related literature to individuals in Hanoi who participated in our class discussions and to provide the ULSA School of Social Work with some literature as well. Subsequently a variety of texts related to social work field supervision and field internship were shipped to the Hanoi participants and their School of Social Work. While they benefited from the cross-cultural exchange, MUN students benefited more because the learning parallels the North American emphasis for social work practitioners to become culturally sensitive (Lum, 2007). It was also recognize that MUN students and faculty have better access to educational resources. It was important, then, to recognize the inherent vulnerability of the individuals in Hanoi and "level the playing field" by offering perceivably more (materialistically) than we received. This gesture provided more balance in the partnership.

\section{Conclusions}

Was the project a successful and should it be repeated throughout other levels of post-secondary education? An opportunity exists for further cross-cultural exchange which can be supported with funding to explore and investigate classroom learning and teaching opportunity on a larger scale. Given that many of the universities in the Global South do not have advanced technological resources, how can research projects such as this support their learning and teaching opportunities? Should there be considerations to explore other universities located in the Caribbean and in South and Central America, where the time zones are closer to the NL time zones? Would this facilitate easier scheduling of classes and likely produce more collaborative partners? Based on feedback from the participants, this experiential learning and teaching engagement was beneficial for students, practitioners, and faculty. The successful dialogue and shared discussions between the two groups from the universities demonstrate the importance of innovative learning and teaching practices. The discussions were rich with unique cultural exchanges that contributed to individuals' understanding of social policy, government and community support, values placed on social workers, and ethic of social work practice in both Hanoi, Vietnam, and St. John's, Newfoundland. The project exceeded expectations and has left a lasting impression on groups of individuals from two different universities in two different countries who attended classes simultaneously in spite the geographic and time zone differences. Participants demonstrated keen interest and enthusiasm for this innovative and educational experience from a cross-cultural perspective. In that sense, the project has helped to solidify the ongoing international collaborative relationship between MUN's School of Social Work and ULSA's School of Social Work, and we must continue to foster these gains.

\section{Acknowledgments}

Instructional Development Office (Ms. Joyce Fewer) and Dr. Doreen Neville, (Memorial University of Newfoundland), Prof. Huong, Dr. Nguyen Trung Hai, (University of Labor and Social Affairs), student and practitioner participants.

\section{References}

Altbach, P. (2002). Perspectives on internationalizing higher education. International Higher Education, 27, 6-8.

Anucha, U. (2008). Building equitable north-south collaborations: The social work in Nigeria project. E-magined: Canadian e-Magazine of International Education at York University, 1(3). Retrieved from $\mathrm{http}: / /$ emagined.apps01.yorku.ca/new-and-innovative-practices/building-equitable-north-south-collaborationsthe-social-work-in-nigeria-project/

Arkoudis, S., Watty, K., Baik, C., Yu, X., Borland, H., Chang, S., ... Pearce, A. (2013). Finding common ground: Enhancing interaction between domestic and international students in higher education. Teaching in Higher Education, 18, 222-235. http://dx.doi.org/10.1080/13562517.2012.719156

Bohemia, E., \& Ghassan, A. (2012). Globally networked collaborative learning in industrial design. American Journal of Distance Education, 26, 110-125. http://dx.doi.org/10.1080/08923647.2012.663678

Brydon, K., Kamasua, J., Flynn, C., Mason, R., Au, R., Ayius, D., \& Hampson, R. (2012). Developing an international social work education collaboration: A partnership approach between Monash University, Australia and University of Papua New Guinea. International Social Work, September 12, 2012, 1-21. 
http://dx.doi.org/10.1177/0020872812444939

Dean, Y. (2013). The experience of female academics teaching social work in the global south. (Doctoral dissertation). University of Calgary, Canada. Retrieved from http://theses.ucalgary.ca/bitstream/11023/449/2/ucalgary_2013_dean_yasmin_thesis.pdf

Durant, A., Rose, W., Mann, C., \& Stix, J. (2007). Multi-university internet video-conferencing course provides novel approach to student-directed learning. The Leading Edge, 26, 1320-1321. http://dx.doi.org/10.1190/1.2794397

Duvvury, N., Carney, P., \& Minh, N.H. (2012). Estimating the cost of domestic violence against women in Viet Nam. New York, NY: UN Women Headquarters. Retrieved from http://www.unwomen.org/en/digital-library/publications/2013/2/estimating-the-cost-of-domestic-violence-aga inst-women-in-viet-nam

Feast, V., \& Bretag, T. (2005). Responding to crisis in transnational education: New challenges for higher education. Higher Education Research and Development, 24, 63-78. http://dx.doi.org/10.1080/0729436052000318578

Fry, J. M., \& Hin, M. K. T. (2006). Peer coaching with interactive wireless technology between student teachers: Satisfaction with role and communication. Interactive Learning Environments, 14, 193-204. http://dx.doi.org/10.1080/10494820600852969

Gein, L., Taylor S., Barter K., Nguyen T., Bui M., \& Nguyen L. (2007). Poverty reduction by improving health and social services. Nursing and Health Sciences, 9(4), 304-309. http://dx.doi.org/10.1111/j.1442-2018.2007.00365.x

Gouthro, P. A. (2004). Assessing power issues in Canadian and Jamaican women's experiences in learning via distance in higher education. Teaching in Higher Education, 9, 449-461. http://dx.doi.org/10.1080/1356251042000252381

Government of Newfoundland and Labrador. (2007). Diversity - "Opportunity and growth": An Immigration strategy for Newfoundland and Labrador. Retrieved from www.nlimmigration.ca/media/12684/strategydoc_mar07.pdf

Government of Newfoundland and Labrador. (n.d.). Geography. Retrieved from http://www.newfoundlandlabrador.com/AboutThisPlace/Geography

Gregersen, T., \& Youdina, T. (2008). An intercultural communication event via video bridge: Bringing Russian and American students together. International Journal of Teaching \& Learning in Higher Education, 20, 262-266.

Harkins, M. J., \& Nobes, C. (2008). A multifaceted approach to cross-border programmes: Expanding educational boundaries. Convergence, 41(2/3), 143-154.

Hrastinski, S. (2006). The relationship between adopting a synchronous medium and participation in online group work: An explorative study. Interactive Learning Environments, 14, 137-152. http://dx.doi.org/10.1080/10494820600800240

Kan, K. H. (2011). Meeting face to face = seeing eye to eye?: Interglobal dialogue via videoconference. International Journal of Education \& the Arts, 12(10), 1-23.

Kreitzer, L., \& Wilson, M. (2010). Shifting perspectives on international alliances in social work: Lessons from Ghana and Nicaragua. International Social Work, 53(5), 701-719. http://dx.doi.org/10.1177/0020872810371205

Law, E. L.-C., \& Nguyen-Ngoc, A. V. (2009). Analysis of online facilitators' social relations and facilitating styles in cross-cultural computer-supported collaborative learning. Technology, Instruction, Cognition \& Learning, 6, 315-332.

Lum, D. (2007). Culturally competent practice: A framework for understanding diverse groups and justice issues (3rd ed.). Belmont, CA: Brooks/Cole.

Meyer, K. (2004). Evaluating online discussions: Four different frames of analysis. Journal of Asynchronous Learning Networks, 8(2), 101-114.

Mukherjee, D. (2011). Principles of effective transnational networking for global social work education: A case study. Journal of Global Social Work Practice, 4(1). Retrieved from http://www.globalsocialwork.org/vol4no1/Mukherjee.html

Pelech, W., \& Macpherson, S. (2009). The global classroom: An opportunity for empowerment or exploitation? International Journal of Learning, 16(8), 301-311. 
Perraton, H. (2000). Open and distance learning in the developing world. London, U.K.: Routledge.

Reed, J., \& Woodruff, M. (1995). Using compressed video for distance learning. Retrieved from http://www.kn.pacbell.com/wired/vidconf/Using.html

Rumble, G. (2001). Just how relevant is e-education to global education needs? Open Learning, 16, $223-232$. http://dx.doi.org/10.1080/02680510120084940

Rye, S. A., \& Støkken, A. M. (2012). The implications of the local context in global online education. International Review of Research in Open and Distance Learning, 13(1), 191-206.

Sandmann, L. R., Reischmann, J., \& Kim, Y. S. (2007). Emerging adult educators' experiences in an international on-line forum. Convergence, 40(1/2), 25-39.

Scott, P., Castañeda, L., Quick, K., \& Linney, J. (2009). Synchronous symmetrical support: A naturalistic study of live online peer-to-peer learning via software videoconferencing. Interactive Learning Environments, 17, $119-134$. http://dx.doi.org/10.1080/10494820701794730

Statistics Canada. (2010). Estimates of population, by age group and sex for July 1, Canada, provinces and territories, annual (CANSIM Table 051-0001). Ottawa: Statistics Canada.

United Nations Office on Drugs and Crime. (2011). Preventing and responding to domestic violence trainees 's manual for law enforcement and justice sectors in Vietnam edition 2. Retrieved from http://www.unodc.org/documents/southeastasiaandpacific//2011/09/domestic-violence/Trainee_manual_in_En glish_6-5-11_.pdf

Vincent, N. J. (2010). The development of an interdisciplinary study abroad MSW course: An emergent model. Journal of Global Social Work Practice, 3(2). Retrieved from http://www.globalsocialwork.org/vol2no1_Vincent.html 